\title{
Electrodeposited Copper Foams as Substrates for Thin Film Silicon Electrodes
}

\author{
Fulya Dogan $^{\mathrm{a}}$, Liurukara D. Sanjeewa ${ }^{\mathrm{b}}$, Shiou-Jyh Hwu ${ }^{\mathrm{b}}$, J. T. Vaughey ${ }^{\mathrm{a}}$ \\ ${ }^{a}$ Chemical Sciences and Engineering Division, Argonne National Laboratory, \\ 9700 South Cass Avenue, Argonne, IL 60439, USA \\ ${ }^{\mathrm{b}}$ Department of Chemistry, Clemson University, Clemson, SC, 29634, USA
}

\begin{abstract}
* To whom correspondence should be directed. Email: vaughey@anl.gov
\end{abstract}

\begin{abstract}
Although a significant amount of effort has been put into investigating elemental silicon as a lithium-ion battery anode material, limited progress has occurred in translating these results to create a long lived electrode. Several electrode level solutions have been reported including utilizing Si nanowires, thin films, and nanoparticle assemblies, where the physical diffusion distances are kept very short. For thin film based electrodes, the benefits of the simplified structure of the electrode are countered by the low surface area and low silicon loadings. In this study we have utilized electrodeposition techniques to deposit silicon films on a porous copper substrate. This greatly increases the electrode surface area and loadings while maintaining the advantages of a thin film electrode. Using 3d- silicon electrodes without a binder or conductive matrix, stable capacities of $\sim 1000 \mathrm{mAh} / \mathrm{g}$ have been achieved. In general, electrodes with lower loadings of active silicon $\left(<1 \mathrm{mg} / \mathrm{cm}^{2}\right)$ displayed better rate capability than electrodes with higher loadings $\left(>2.5 \mathrm{mg} / \mathrm{cm}^{2}\right)$.
\end{abstract}

\subsection{Introduction}

Silicon is considered a promising alternative anode material to graphite in Li-ion batteries for many reasons including its high specific capacity (gravimetric $>3500 \mathrm{mAh} / \mathrm{g}$, volumetric $>8200$ $\mathrm{mAh} / \mathrm{cm}^{3}$ ), availability, and low charge/discharge voltage at room temperature [1,2]. Together, with a high capacity cathode and an advanced cell design, very high energy batteries can be 


\subsection{Experimental}

Electrode films were created by electrodeposition of silicon from a bath containing $1 \mathrm{M} \mathrm{SiCl}$ (Aldrich, 99\%), 0.5M (TBA)Cl (Aldrich, 98\%) in propylene carbonate (PC, anhydrous, Aldrich, $>99.7 \%)$ ). The materials were used as received. The films were deposited onto a porous copper foam substrate at a constant voltage of $-3.4 \mathrm{~V}$ vs Pt, based on cyclic voltammetry studies of the solution. Platinum reference and counter electrodes were used for electrodeposition and all the experiments were carried out under an argon atmosphere at room temperature. The copper foam substrates were prepared by depositing copper on a copper metal foil using a method previously reported [15]. 
Electrochemical cells (Hohsen, 2032) were constructed using the electrodeposited silicon films as the cathode and lithium metal as the anode. The cells were assembled in $1.2 \mathrm{M} \mathrm{LiPF}_{6}$ in 3:7 ethylene carbonate (EC): ethyl methyl carbonate (EMC) (wt\%) using Celgard 2325 separators More specific details are given in ref [16]. Cells were cycled at $50 \mu \mathrm{A} / \mathrm{cm}^{2}$ in the window 0.01$1.5 \mathrm{~V}$ and $100 \mu \mathrm{A} / \mathrm{cm}^{2}$ in the window $0.12-1.5 \mathrm{~V}$ vs. $\mathrm{Li}$ in the first and remaining cycles, respectively until cell failure.

\subsection{Results and Discussion}

For many interfacial electrochemical materials studies, thin films electrodes are ideal because of their well-defined surface area, the absence of binder or conductive additive, and experimental control over crystallinity $[3,7,8,13]$. These advantages can help researchers better understand various electrode processes, surface reactions, and the effect of cycling on specific physical characteristics of the active material. In addition, depending on the deposition process used, the electrode substrate or current collector for the electrodes can also be varied, allowing for different electrode designs to be evaluated that have strong connectivity between the active material and the current collector [11-14]. This attribute has been taken advantage of to test designs based on nanostructured materials (e.g. VLS Si nanowires), porous electrodes (e.g. 3dom or metal foam-based electrodes) or X-ray transparent electrodes needed for in-situ experiments [17]. Taking advantage of the solubility of silicon tetrachloride in certain non-aqueous solvents, conformal $\mathrm{Si}$ anode films can be created that demonstrate good power and capacity retention. Combining this deposition with a porous current collector, allows much higher loadings in a similar volume while maintaining the electrochemical testing advantages of thin electrodes.

The synthesis of copper foam current collector studies was carried out under several different deposition conditions [15]. In Figure 1, the images of two different substrates are shown. The porosity is derived from the deposition of copper being templated by the hydrogen bubbles that are evolved at the electrode surface. Longer time yields large bubbles and more porous frameworks.

After the $\mathrm{Cu}$ foam is synthesized, it is immersed in a solution of silicon tetrachloride dissolved in PC using $0.5 \mathrm{M}$ (TBA)Cl as the supporting electrolyte. The electrodes are placed so as to deposit silicon on the working electrode with evolution of chlorine on the counter electrode. 
Cyclic voltammetry with a Pt quasi-reference electrode (QRE) cell was used to study silicon electrodeposition on copper foil in a $0.5 \mathrm{M} \mathrm{TBACl} / \mathrm{PC}$ electrolyte with and without addition of
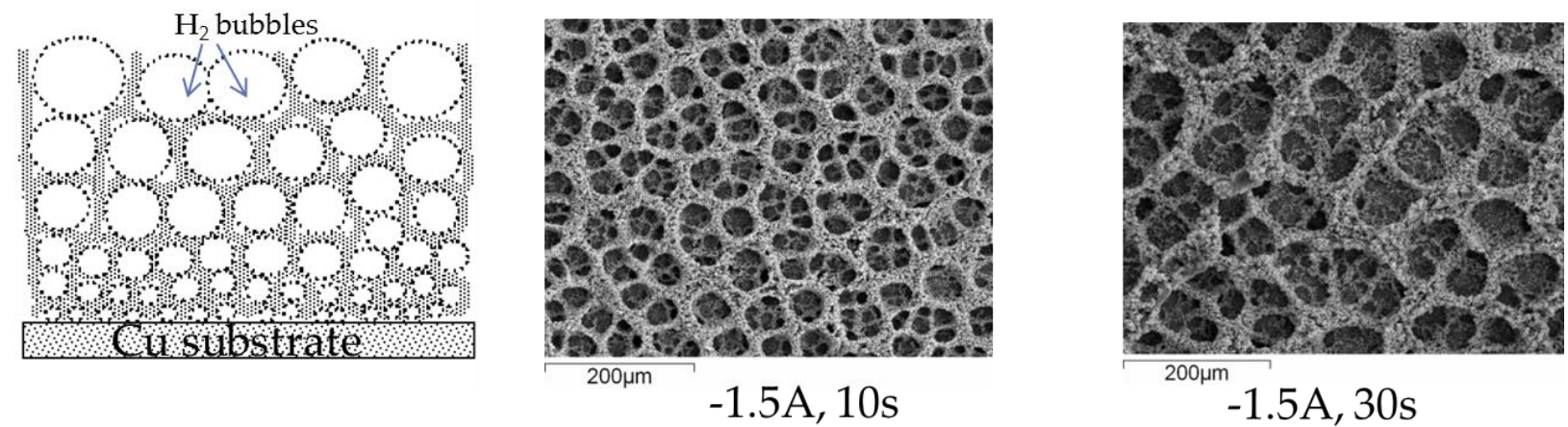

Figure 1. Copper foams prepared by deposition of $\mathrm{Cu}$ from a $0.2 \mathrm{M} \mathrm{CuSO}_{4} / 1.5 \mathrm{M} \mathrm{H}_{2} \mathrm{SO}_{4}$ solution onto a copper foil. At fixed current, the deposition time can be used to control the pore size.

$\mathrm{SiCl}_{4}$. In Figure 3, a comparison of the two voltammograms suggests that the silicon electrodeposition occurs with a cathodic peak around $-3.4 \mathrm{~V}$. The increase of cathodic current around $-4.2 \mathrm{~V}(0.1 \mathrm{~V}$ vs $\mathrm{Li} / \mathrm{Li}+)$, beyond the onset of silicon deposition, has been attributed to decomposition of PC and supporting electrolyte cations. The film was created at a constant potential of $-3.4 \mathrm{~V}$ at a constant current density of $-10 \mathrm{~mA} / \mathrm{cm}^{2}$ for two hours. Analysis of the cyclic voltammetry data suggest that following reactions are taking place on working and counter electrodes;

$$
\begin{gathered}
\mathrm{SiCl}_{4}+4 \mathrm{e}^{-} \rightarrow \mathrm{Si}+4 \mathrm{Cl}^{-} \text {(working electrode) } \\
4 \mathrm{Cl}^{-} \rightarrow 2 \mathrm{Cl}_{2}+4 \mathrm{e}^{-} \text {(counter electrode) }
\end{gathered}
$$

A comparison of the number of Coulombs passed during thin film deposition for the potenstiostatic electrodeposition using Faraday's law when compared to the amount of lithium stored in the silicon on the first electrochemical lithiation gives an average efficiency for the electrochemical silicon deposition the $\mathrm{SiCl}_{4} / \mathrm{PC}$ solution of around 35\%, consistent with the reported values. This lower silicon deposition efficiency has been correlated in the literature with electrolyte decomposition and side reactions related to the reactivity of $\mathrm{SiCl}_{4}[12,13]$. 


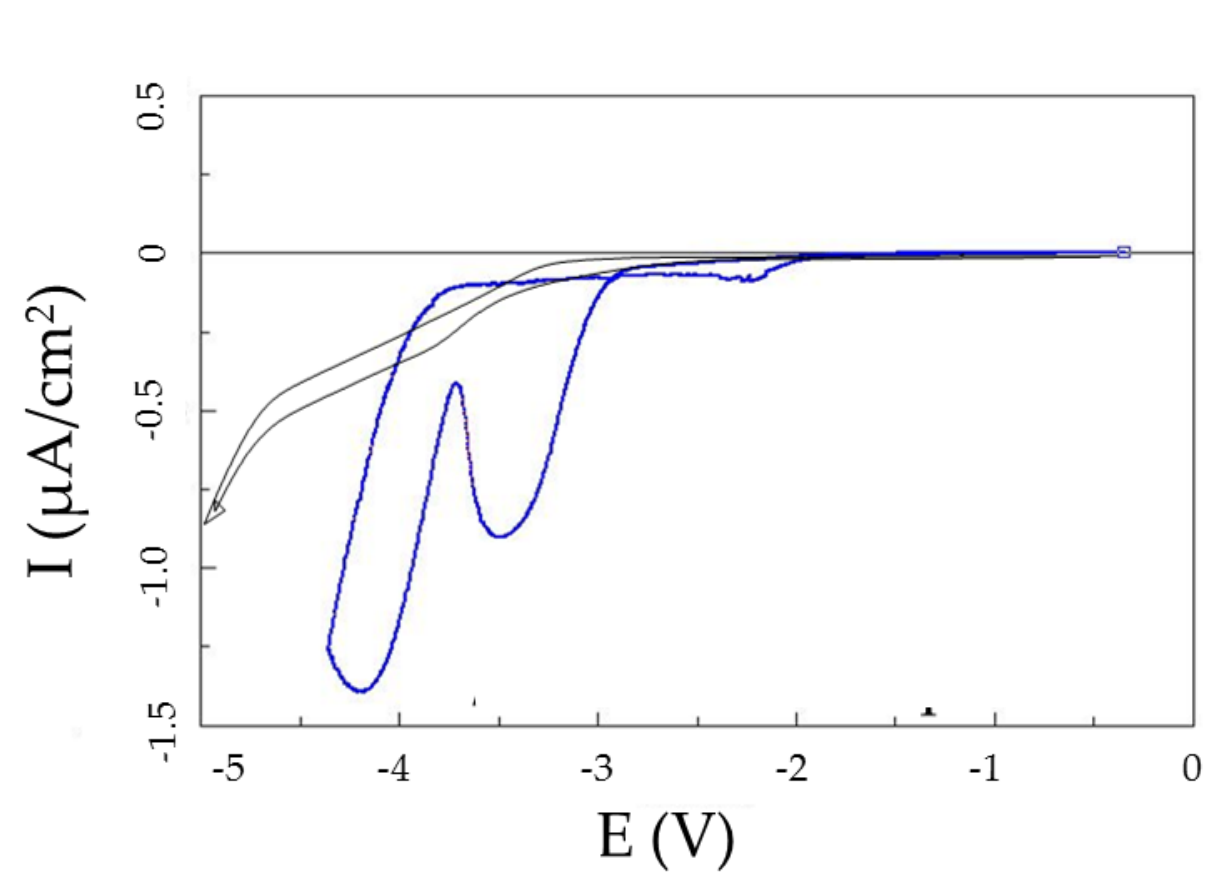

Figure 2. Cyclic Voltammograms for silicon electrodeposition solutions, dashed line shows supporting electrolyte and solvent, solid line shows silicon chloride, supporting electrolyte and solvent (scan rate of $5 \mathrm{mV} / \mathrm{s}$ ).

SEM images of the silicon thin films on copper foam show non-uniform silicon deposits with plate-like structures with silicon thicknesses varying between $1.5-4 \mu \mathrm{m}$. With potentiostatic electrodeposition, the current densities observed for TBACl solutions are between -10 to -15 $\mathrm{mAcm}^{-2}$. X-Ray diffraction examination of the electrodeposited silicon films showed a nanocrystalline or amorphous structure. EDX analysis of the thin films indicates silicon is the main component with minor amounts of chloride, oxygen, and carbon. The oxygen in the films is probably due to side reactions between the $\mathrm{SiCl}_{4}$ and any residual moisture in the system (contaminants, solvent decomposition products) while the chloride and carbon are attributed to electrolyte breakdown products held within the microstructure of the film $[12,13]$. In half-cells, these porous films exhibited first cycle irreversible capacities near $40 \%$, consistent with literature reports. Initial capacities were used to estimate silicon loadings. After break-in, as shown in Figure 4, the cells were found to exhibit extremely stable capacities, under the conditions used, especially in comparison to conventional laminates and thicker films. The cells 

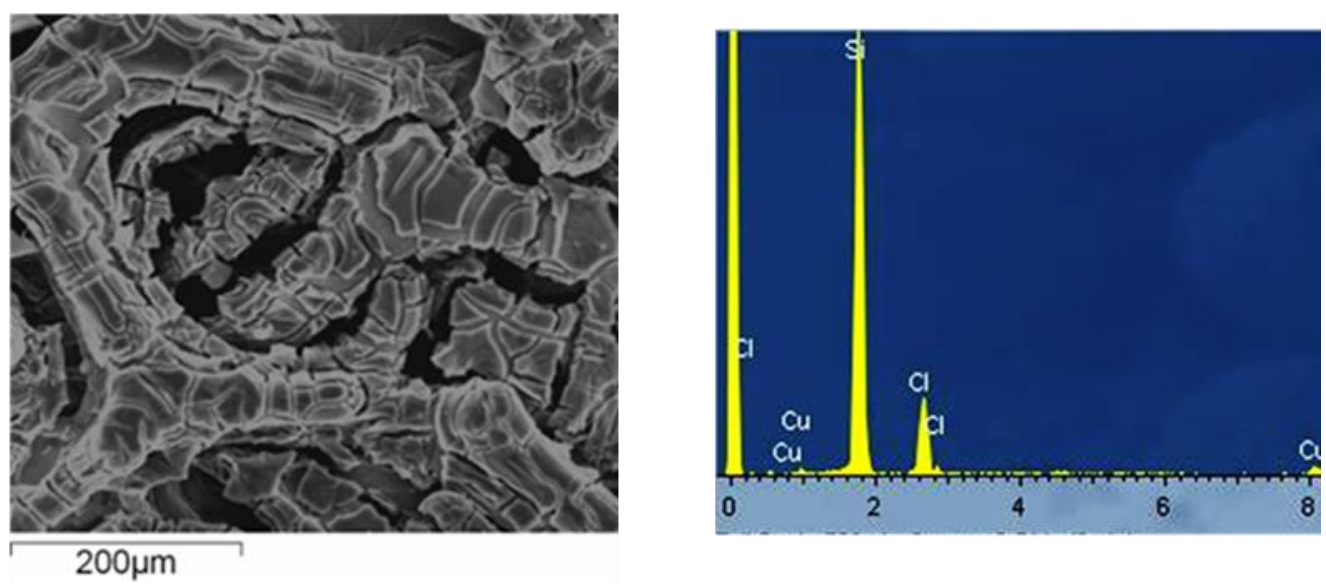

Figure 3. SEM images of copper foam after silicon electrodeposition. An EDX spectrum of the silicon thin film electrodeposited on the copper foam shows predominantly copper and silicon. The chloride is believed to arise from insoluble electrolyte breakdown products that are present in the films microstructure.
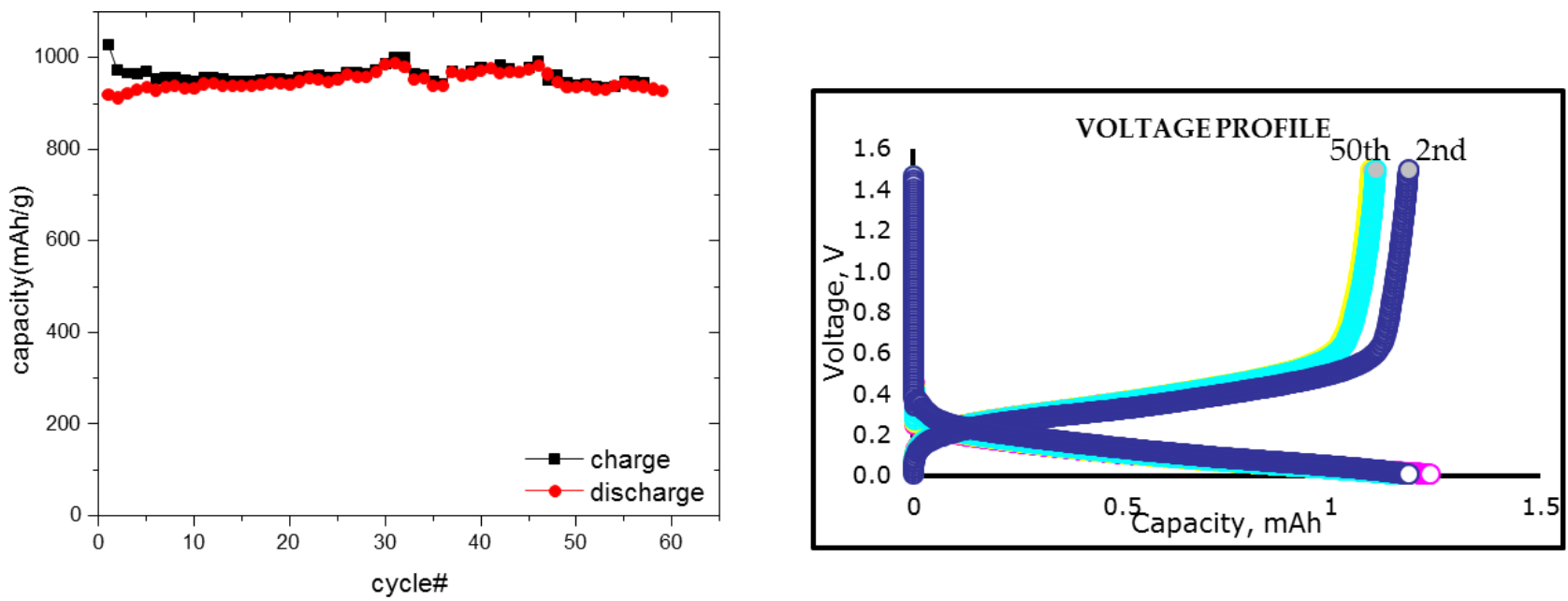

Figure 4 Charge/Discharge and voltage profile plot for a porous silicon thin film electrode. The capacity plot is after first cycle and the first cycle ICL is around $70 \%$ for this specific sample. The loss in capacity can be mainly attributed to SEI formation and surface silicon oxide species. were cycled at $50 \mu \mathrm{A} / \mathrm{cm}^{2}$ in the window $0.01-1.5 \mathrm{~V}$ and $100 \mu \mathrm{A} / \mathrm{cm}^{2}$ in the window $0.12-1.5 \mathrm{~V}$ vs. Li in the first and remaining cycles, respectively until cell failure. The specific current 
density after 1st cycle is $0.08 \mathrm{~A} \mathrm{~g}-1$. Typical cycling capacities were found to be $1.2 \mathrm{mAh}(0.75$ $\mathrm{mAh} / \mathrm{cm}^{2}$ ). Thicker films (>2 $\mu \mathrm{m}, 2.5 \mathrm{mg} / \mathrm{cm}^{2}$ ) showed higher initial areal capacities but failed faster due to spalling, cracking, and loss of active material. Structural and electrochemical characterization studies on the films with high loading levels $\left(>2.5 \mathrm{mg} / \mathrm{cm}^{2}\right)$ showed formation of inactive surface species (e.g. $\mathrm{SiO}_{2}$, electrolyte breakdown products) and correspondingly lower capacity retention. With these synthetic techniques and using the electrochemical performance as a judgement criteria, films produced with these methods have a loading level maximum of $1.5 \mathrm{mg} / \mathrm{cm}^{2}$.

\subsection{Conclusions}

Utilizing a porous copper foam as the substrate for an electrodeposited silicon electrode, we have demonstrated that an electroactive silicon thin film can be deposited into confined space. Compared to conventional flat silicon electrodes, these films had higher loadings but displayed very good cycling stability in convectional carbonate electrolytes. We anticipate that since the porous electrode used was cycled in organocarbonate electrolytes and that these materials are known to form relatively thick SEI layers. Future work will focus on using FEC-based systems which have been reported to form significantly denser SEI films which should be advantageous to the electrochemical cycling stability as the internal porous structure of the electrode will not be as obstructed.

\subsection{Acknowledgments}

The authors would like to thank the Assistant Secretary for Energy Efficiency and Renewable Energy, Office of Vehicle Technology of the U.S. Department of Energy (DOE), under the Batteries Materials Research (BMR) Program for their support. The submitted manuscript has been created by UChicago Argonne, LLC, Operator of Argonne National Laboratory ("Argonne"). Argonne, a U.S. Department of Energy Office of Science laboratory, is operated under Contract No. DE-AC02-06CH1 1357. The U.S. Government retains for itself, and others acting on its behalf, a paid-up, nonexclusive, irrevocable worldwide license in said article to 
reproduce, prepare derivative works, distribute copies to the public, and perform publicly and display publicly, by or on behalf of the Government.

\subsection{References}

[1] M. N. Obrovac, V. L. Chevrier Chem. Rev. 114 (2014) 11444.

[2] B. Liang, Y. Liu, Y. Xu J. Power Sources 267 (2014) 469.

[3] Y. -M. Kang, S. -M Lee, S. -J Kim, G. -J. Jeong, M. -S. Sung, W. -U Choi, S.-S. Kim Electrochem. Comm. 9 (2007) 959.

[4] V. L. Chevrier, Li Liu, D. Ba Le, J. Lund, B. Molla, K. Reimer, L. J. Krause, L. D. Jensen, E. Figgemeier, Kevin W. Eberman J. Electrochem. Soc., 161 (2014) A783.

[5] R. Miyazaki, N. Ohta, T. Ohnishi, I. Sakaguchi, K. Takada J. Power Sources 272 (2014) 541.

[6] T. Kim, S. Park, and S. M. Oh J. Electrochem. Soc. 154 (2007) A1112.

[7] A. A. Hubaud, Z. Z. Yang, D. J. Schroeder, F. Dogan, L. Trahey, J. T. Vaughey J. Power Sources 282 (2015) 639.

[8] V. A. Sethuraman,V. Srinivasan, J. Newman J. Electrochem. Soc., 160 (2013) A394.

[9] B. Key, R. Bhattacharyya, M. Morcrette, V. Sezne, J.-M Tarascon, C. P. Grey J. Am. Chem. Soc. , 131 (2009), 9239.

[10] B. Key, M. Morcrette, J.-M Tarascon, C. P. Grey J. Am. Chem. Soc., 133 (2011), 503.

[11] X. Su , Q. Wu , J. Li , X. Xiao, A. Lott, W. Lu, B. W. Sheldon, J. Wu Adv. Energy Mater. 4 (2014) 1300882.

[12] M.T. McDowell , S. W. Lee, W. D. Nix, Y. Cui Adv. Mater. 25 (2013) 4966.

[13] R. Teki, M. K. Datta, R. Krishnan, T. C. Parker, T. -M. Lu, P. N. Kumta, N. Koratkar small 5 (2009) 2236.

[14] F. Dogan, C. Joyce, J. T. Vaughey J. Electrochem. Soc. 160 (2013) A312.

[15] L. Trahey, J. T. Vaughey, H. H. Kung, M. M. Thackeray J. Electrochem. Soc. 156 (2009) A385. 
[16] S. Neuhold, J. T. Vaughey, C. Grogger, C. M. López J. Power Sources 254 (2014) 241.

[17] C. Joyce, L. Trahey, S. A. Bauer, F. Dogan, J. T. Vaughey J. Electrochem. Soc. 159 (2012) A909. 